\title{
Removal of formaldehyde, methanol, dimethylether and carbon monoxide from waste gases of synthetic resin-producing industries
}

\author{
Ó.J. Prado, M.C. Veiga, C. Kennes \\ Chemosphere, Volume 70, Issue 8, February 2008, Pages 1357-1365
}

DOI: 10.1016/j.chemosphere.2007.09.039

\begin{abstract}
The removal of mixtures of gas-phase pollutants released from formaldehyde- and formaldehyde resin-producing industries was studied in different bioreactor systems. The waste gases contained formaldehyde, methanol, dimethylether and carbon monoxide. The use of a hybrid two-stage bioreactor, composed of a biotrickling filter and a conventional biofilter connected in series, led to very high elimination capacities and removal efficiencies close to $100 \%$ for overall pollutant loads exceeding $600 \mathrm{~g} \mathrm{~m}^{-3} \mathrm{~h}^{-1}$. The presence of low concentrations of dimethylether in the gaseous mixture did not have a significant effect on the removal of formaldehyde or methanol under our operating conditions, although moderate concentrations of these compounds did negatively affect the biodegradation of dimethylether. When a mixture of all four compounds, at concentrations around $100,100,50$ and $50 \mathrm{mg} \mathrm{m}^{-3}$ for formaldehyde, methanol, carbon monoxide and dimethylether, respectively, was fed to a conventional biofilter, removal efficiencies higher than $80 \%$ were obtained for the first three pollutants at empty bed retention time values above $30 \mathrm{~s}$. On the other hand, dimethylether was removed to a lower extent, although its reduced environmental impact allows to conclude that these results were satisfactory.
\end{abstract}

\section{Keywords}

Biofilter; Biotrickling filter; Carbon monoxide; Dimethylether; Methanol; Waste gas

\section{Introduction}

The number of full-scale applications of biofilters and biotrickling filters has significantly increased over the past 20 years. Over the past decades, these systems have widely been employed to control odor emissions in wastewater treatment plants and composting facilities, among others (Kennes and Thalasso, 1998 and Kennes and Veiga, 2001). Moreover, nowadays their application has been extended to several industrial facilities as they offer a reliable, cost-effective alternative to traditional physicochemical gas treatment technologies (van Groenestijn, 2005). Recent research studies are focusing on the development of more efficient biocatalysts (Kennes and Veiga, 2004), new filter beds (Kennes and Veiga, 2002), and on the application of bioprocesses to a wider range of pollutants (Philip and Deshusses, 2002, Jin et al., 2005 and Chen et al., 2006). 
A series of previous studies have been developed by our research group in order to implement bioreactor technologies for the treatment of off-gases from formaldehydeand formaldehyde resin-producing industries. The number and global amount of waste gases emitted to the atmosphere from such facilities has increased to a great extent over the past four decades. Our previous work focused on the biological treatment of the two major compounds present in off-gases of these industries, namely formaldehyde and methanol. Those pollutants are released from fugitive emissions as well as from unit operations during production processes. However, other pollutants as dimethylether and carbon monoxide appear in some gaseous emissions together with formaldehyde and methanol. Although all four compounds have proven to be biodegradable (Meyer and Schlegel, 1979, Prado et al., 2005a and Eiroa et al., 2006), the elimination of mixtures of two or more of them in gas-phase bioreactors has hardly been studied. While several studies have been published on the treatment of formaldehyde (Máckowiak, 1992 and Prado et al., 2003) and methanol (Shareefdeen et al., 1993, Krailas et al., 2000 and Mohseni and Allen, 2000) as single pollutants in gas-phase bioreactors, works reporting the microbial removal of carbon monoxide in such systems are much scarcer (Wolfrum and Watt, 2002 and Wolfrum et al., 2002) and, as far as we know, no research studies have been performed on the removal of dimethylether in bioreactors.

The aim of the present research was to study the biological treatment of gaseous mixtures of formaldehyde, methanol, dimethylether and carbon monoxide in batch assays and, subsequently, in biological reactors, with the purpose of understanding the effect that some of the most important operational parameters (as the waste gas load and composition, the empty bed residence time or the supply of a liquid solution) can have on their performance and in order to eventually implement the technology in actual formaldehyde- and resin-producing industries. Even though, commonly, low pollutant concentrations are emitted from these sources, these may correspond to very high pollutant loads when small bioreactors are employed as treatment technology. Most of the experiments presented herein were carried out under relatively high pollutant loads, corresponding to small bioreactors treating low pollutant concentrations. These bioreactors are generally preferred over bigger systems, as both the investment and the operation costs are significantly reduced.

\section{Materials and methods}

\subsection{Bioreactors}

A series of biofilters and biotrickling filters were used throughout this research. The general characteristics of the systems have been described elsewhere (Prado et al., 2004a). The conventional biofilters had a packing volume between 1.0 and $3.4 \mathrm{l}$, while the biotrickling filters contained between 1.0 and 2.0 l packing material. Lava rock was employed as filter bed in all the studies. Its main physico-chemical properties were described in Prado et al. (2004a). The bioreactor systems were operated with a downward flow, at room temperature, and were fed with a nutrient solution described elsewhere (Estévez et al., 2005). 


\subsection{Biocatalysts}

Two different inocula were used for the batch studies. In most of the experiments, sludge from the wastewater treatment plant of a formaldehyde resin-producing facility was employed. The main physico-chemical characteristics of the sludge have been described earlier (Prado et al., 2004a). No in-depth microbiological analysis was performed on this sludge, though microscope observations showed that it contained a wide variety of microorganisms, predominantly bacteria. The sludge was also employed as inoculum in all the bioreactor studies described herein. Additionally, a pure Oligotropha carboxidovorans OM5 culture was employed for a series of batch studies. O. carboxidovorans OM5 is a carboxidotrophic Gram-negative bacillus able to catalyze the biodegradation of carbon monoxide ( Meyer and Schlegel, 1979).

\subsection{Batch experiments}

The batch assays were carried out in 635-ml glass vials, containing $100 \mathrm{ml}$ inoculum and the same nutrient solution as for the bioreactor studies (Estévez et al., 2005). Before starting the experiments, the $\mathrm{pH}$ was adjusted at 7.5 and distilled water was added until a final volume of $150 \mathrm{ml}$ was reached. After adding the substrate (formaldehyde, methanol, dimethylether or carbon monoxide), the vials were sealed and maintained at $30{ }^{\circ} \mathrm{C}$ with constant shaking at $200 \mathrm{rpm}$. Gas samples of the headspace were periodically taken in order to measure the substrate concentration. Pollutant concentrations in the liquid could be calculated by means of Henry's law. All the vials were prepared in duplicate, including "blank" and "control" assays. "Blank" vials were identical to the experimental vials with the highest pollutant concentration, but had been previously submitted to sterilization at $120^{\circ} \mathrm{C}$ for $30 \mathrm{~min}$. "Control” vials had also that same composition, but contained distilled water instead of sludge.

\subsection{Analytical methods}

A HP-6890 GC equipped with a TCD (thermal conductivity detector) and a FID (flame ionization detector), operating in splitless mode, was employed to measure the gasphase pollutant concentrations. The system contained two GC-columns connected in series. First, a $30 \mathrm{~m} \times 0.53 \mathrm{~mm}$ HP-PLOT Q column was used to detect formaldehyde, methanol and dimethylether with a FID. Afterwards, a $15 \mathrm{~m} \times 0.53 \mathrm{~mm}$ HP-PLOT Molecular Sieve 5A was used for carbon monoxide determination with a TCD. The chromatographic conditions used for formaldehyde, methanol and dimethylether detection have been described elsewhere (Prado et al., 2004b). The conditions employed for carbon monoxide determination can be found in Prado et al. (2005a). Calibrations were performed as described in Prado et al. (2002). Drain liquid samples were periodically tested for $\mathrm{pH}$, using an Ingold U455-S7 electrode connected to a Crison $\mathrm{pH}$-meter 507. A U-tube glass manometer was used to measure the pressure drop. Formaldehyde concentration in the liquid phase was determined spectrophotometrically, according to Nash (1953). The measurement of methanol in the liquid phase was performed by means of a HP-5680 GC equipped with a $30 \mathrm{~m} \times 0.25 \mathrm{~mm}$ Innowax column and a FID. Injector and detector temperatures were set at 250 and $270{ }^{\circ} \mathrm{C}$, respectively. The initial oven temperature was set at $90{ }^{\circ} \mathrm{C}$, with an immediate increase of $3{ }^{\circ} \mathrm{C} \mathrm{min}^{-1}$, up to $100{ }^{\circ} \mathrm{C}$. 


\section{Results and discussion}

\subsection{Batch studies}

It may be expected that sludges generated in the wastewater treatment plants of facilities in which specific pollutants are produced contain considerable amounts of microorganisms able to perform their biodegradation, as long as those compounds are to some extent biodegradable and have a natural tendency to transfer to the liquid phase. The first study presented herein was aimed at evaluating the capacity of a sludge obtained from the wastewater treatment plant of a formaldehyde resin-producing industry to perform the biodegradation of formaldehyde, methanol, dimethylether and carbon monoxide individually. All these compounds commonly appear in the gaseous emissions of the afore mentioned industry, up to concentrations of about $100 \mathrm{mg} \mathrm{m}^{-3}$ for formaldehyde and methanol and $50 \mathrm{mg} \mathrm{m}^{-3}$ for dimethylether and carbon monoxide. In previous research carried out in our group, this sludge has proven to efficiently biodegrade mixtures of formaldehyde and methanol in bioreactors (Prado et al., 2004a and Prado et al., 2006). Still, its capacity to eliminate dimethylether and carbon monoxide had not been evaluated nor reported so far. A series of batch assays was setup, using the sludge as biocatalyst, and each of the four mentioned pollutants as carbon source. Additionally, a pure culture of the carboxidotrophic bacterium, $O$. carboxidovorans OM5, was tested as carbon monoxide-degrader. The removal pattern of each compound during these batch studies is shown in Fig. 1.
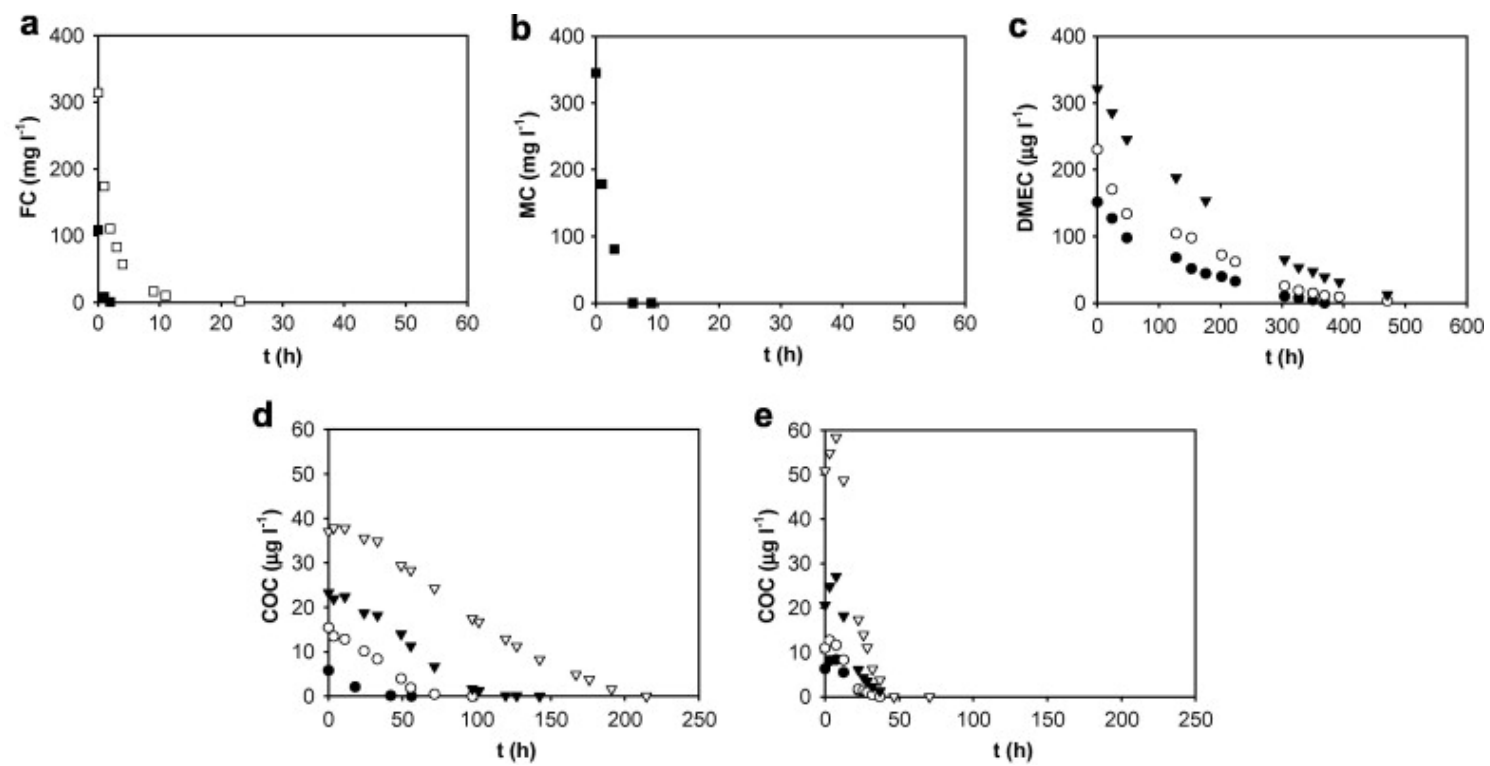

Fig. 1.

Elimination in batch assays of (a) formaldehyde; (b) methanol; (c) dimethylether; (d) carbon monoxide, sludge-catalyzed; (e) carbon monoxide, $O$. carboxidovorans OM5-catalyzed. Each plot shows the removal pattern at different initial substrate concentrations. FC: formaldehyde concentration, MC: methanol concentration, DMEC: dimethylether concentration, COC: carbon monoxide concentration. 
The results presented in Fig. 1a-d prove that the sludge can efficiently carry out the biodegradation of all four pollutants, being formaldehyde and methanol the most readily eliminated. Initial concentrations of those compounds exceeding $300 \mathrm{mg} \mathrm{l}^{-1}$ (in liquid phase) were degraded in less than $12 \mathrm{~h}$, even though the microbial culture had not previously been exposed to their presence in the laboratory. On the other hand, the biodegradation of dimethylether and carbon monoxide by the sludge was significantly slower. Initial dimethylether concentrations around $300 \mu \mathrm{g} \mathrm{l} \mathrm{l}^{-1}$ (in liquid phase) needed 20 days to be fully degraded. Also, initial carbon monoxide concentrations around $40 \mu \mathrm{gl}^{-1}$ (in liquid phase) were totally eliminated only after 10 days. It can be hypothesized that, in the sludge, a more significant growth of formaldehyde- and methanol-degraders takes place than for the other two pollutants. This is a consequence of the lower air/water partition coefficient and higher solubility in water of formaldehyde and methanol compared to dimethylether and carbon monoxide. Their biodegradability by the biomass in the sludge is presumably also higher. Additionally, Fig. 1d and e show that the removal of carbon monoxide significantly improved when a pure O. carboxidovorans OM5 culture was employed as biocatalyst instead of the sludge, even though the VSS concentration of the pure culture was 10 times lower than for the sludge in these experiments. No elimination of any of the substrates was observed in the "blank" and "control" vials (data not shown).

\subsection{Optimization of the treatment of formaldehyde and methanol in a two-stage bioreactor}

The results obtained in previous studies performed with different formaldehyde- and methanol-degrading bioreactor configurations (Prado et al., 2004a, Prado et al., 2005b and Prado et al., 2006) showed that biotrickling filters can commonly achieve higher maximum elimination capacities than conventional biofilters for the elimination of these compounds. Maximum, stable formaldehyde elimination capacities around 40 and $110 \mathrm{~g} \mathrm{~m}^{-3} \mathrm{~h}^{-1}$ were obtained when working with conventional and trickling biofilters, respectively. Also, maximum, stable methanol elimination capacities around 300 and $700 \mathrm{~g} \mathrm{~m}^{-3} \mathrm{~h}^{-1}$ were attained, respectively, in conventional and trickling biofilters. This shows the advantage of continuously supplying a liquid solution, which may serve as a nutrient source but which is also useful to control the $\mathrm{pH}$ of the medium and to remove acidic and toxic metabolites. However, in biotrickling filters, removal efficiencies rarely reach $100 \%$, even at low inlet pollutant loads. In the previously mentioned studies, average removal efficiencies commonly ranged from $70 \%$ to $90 \%$ for both compounds in biotrickling filters. This is probably a consequence of an increased pollutant transfer limitation from the gas phase to the biofilm, due to the presence of a thicker liquid layer than in conventional biofilters. Similar effects have been observed in studies published by other authors (Pedersen et al., 1997, Okkerse et al., 1999, Wolfrum et al., 2002 and Gabriel and Deshusses, 2003). On the other hand, removal efficiencies close to $100 \%$ could generally be achieved in conventional biofilters (Prado et al., 2005b), in which the mass transfer limitation is diminished, at low or moderate inlet pollutant loads.

According to this, it was considered that a promising alternative to improve the treatment of mixtures of methanol and formaldehyde would be using a two-stage hybrid bioreactor system composed of a biotrickling filter connected in series to a biofilter. Such a system would combine the advantages of both individual reactors, achieving high elimination capacities associated to removal efficiencies close to $100 \%$. 
Considering the previous studies, it was expected that most of the removal would take place in the first stage, the biotrickling filter, while the rest of the waste gas would be fully degraded in the second one, the conventional biofilter. The use of multistage bioreactor configurations has proved to be useful in other researches, e.g., when complex mixtures of pollutants, some of which show inhibitory effects when present together, have to be degraded (Chitwood et al., 1999, Ruokojarvi et al., 2001, Li et al., 2003 and Hsu et al., 2004). These systems have also been applied to processes in which the metabolites generated in a first stage have to be treated (Philip and Deshusses, 2002), or for the optimization of the removal of a single compound (Lee, 2003, Spigno et al., 2003 and Choi et al., 2004).

For the present study, a two-stage bioreactor system composed of a biotrickling filter (which served as first stage of the bioreactor) and a conventional biofilter (second stage) connected in series was designed and developed. Each bioreactor was packed with $1 \mathrm{l}$ lava rock, and was continuously operated during 11 months at room temperature, with a downward air flow. The air flow rate supplied to the system was $100 \mathrm{l} \mathrm{h}^{-1}$ during the first 160 days of operation, and $67 \mathrm{l} \mathrm{h}^{-1}$ during the rest of the experiment. The total empty bed retention time (EBRT, defined as the filter bed volume divided by the air flow rate) of the system was $72 \mathrm{~s}$ (36 s in each stage) during the first 160 days, and $108 \mathrm{~s}$ (54 s in each stage) between days 160 and 330. The biotrickling filter was continuously fed $2 \mathrm{l}$ of a nutrient solution, at a recirculation rate of $3 \mathrm{l} \mathrm{h}^{-1}$. The solution was renewed monthly, with its $\mathrm{pH}$ adjusted to 7.5. The biofilter was weekly fed $2 \mathrm{l}$ of that same solution, again, with its $\mathrm{pH}$ adjusted to a value of 7.5. Both reactors had been inoculated with sludge and exposed separately to a mixture of formaldehyde and methanol for more than four months each before they were connected, showing high removal efficiencies. Hence, no start-up phase was observed in the two-stage system. Once the reactors had been connected, pollutant loads of $22 \pm 8 \mathrm{~g}$ (formaldehyde) $\mathrm{m}^{-3} \mathrm{~h}^{-1}$ and $270 \pm 110 \mathrm{~g}$ (methanol) $\mathrm{m}^{-3} \mathrm{~h}^{-1}$ were fed to the combined system, corresponding to loads of $44 \pm 16 \mathrm{~g}$ (formaldehyde) $\mathrm{m}^{-3} \mathrm{~h}^{-1}$ and $540 \pm 220 \mathrm{~g}$ (methanol) $\mathrm{m}^{-3} \mathrm{~h}^{-1}$ fed to the biotrickling filter. As expected, most of the degradation occurred in this first stage, in which removal efficiencies of $88 \pm 10 \%$ and $72 \pm 15 \%$ were obtained for formaldehyde and methanol, respectively (Fig. 2). Hence, the formaldehyde and methanol loads fed to the conventional biofilter were, respectively, $5.4 \pm 4.4$ and $135 \pm 76 \mathrm{~g} \mathrm{~m}^{-3} \mathrm{~h}^{-1}$. Again, as expected, the average removal efficiency of both compounds in the conventional biofilter exceeded 95\%. The EBRTincrease performed on day 160 of operation did not affect the performance significantly. Occasional analyses of formaldehyde and methanol were performed in the liquid drained from both reactors. The results showed that less than 3\% of each pollutant was present in that liquid, proving that no significant amount of any of the compounds was dissolved in the liquid phase. Fig. 2 shows the effect of the pollutant load on the elimination capacity for both compounds during the 11-month experiment. It can be seen that the critical loads of formaldehyde and methanol were not reached for the global system. Hence, it is expected that even higher elimination capacities could be attained in this hybrid system. 

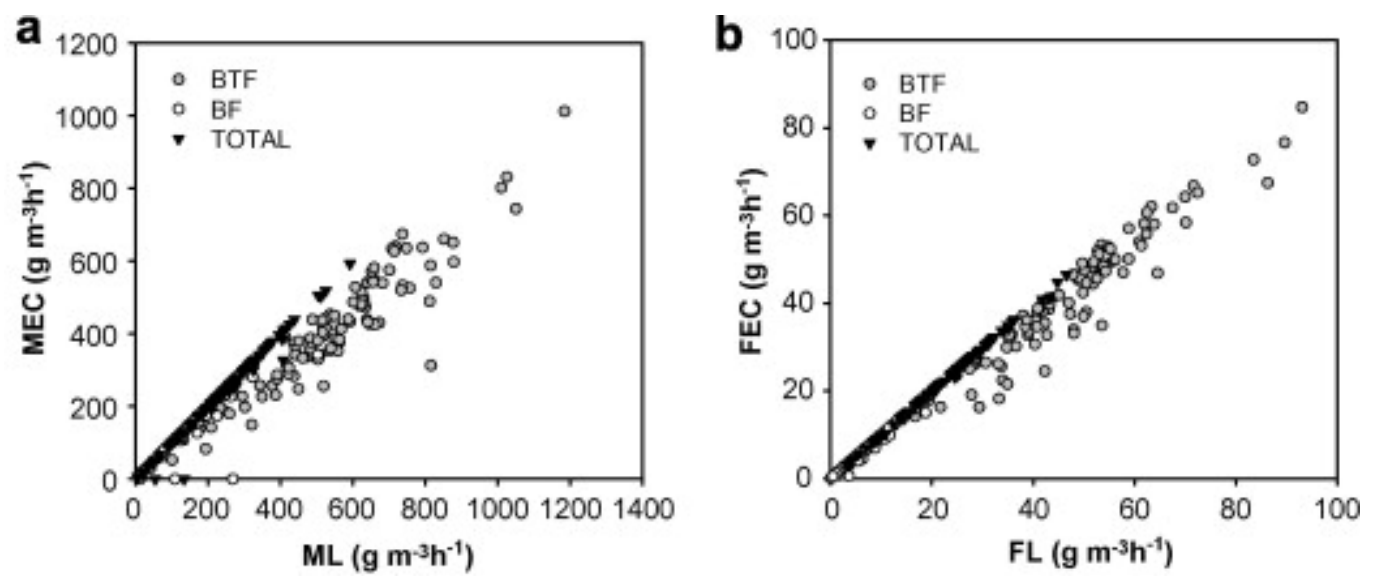

Fig. 2.

Pollutant loads vs elimination capacities of both substrates for the two-stage bioreactor: (a) formaldehyde, (b) methanol. MEC: methanol elimination capacity, ML: methanol load, FEC: formaldehyde elimination capacity, FL: formaldehyde load.

\subsection{Treatment of dimethylether-containing mixtures}

Once the ability of the sludge to biodegrade dimethylether had been proven in batch assays, a new series of studies were started, aimed at evaluating its capacity to treat dimethylether-containing mixtures in bioreactors. As dimethylether alone is not a critical air pollutant, no bioreactor studies were carried out with this compound alone. Instead, its biodegradation was studied in the presence of formaldehyde and methanol, the main compounds emitted from formaldehyde resin-producing industries.

In a first experiment, the extent of elimination of mixtures of methanol and dimethylether was evaluated in a conventional biofilter packed with $3.4 \mathrm{l}$ lava rock. The main objective of this experiment was to check the effect of supplying different methanol loads on the removal of dimethylether in a biofilter. The system was operated at an EBRT of $91 \mathrm{~s}$ for two months. The bioreactor was weekly fed the previously mentioned liquid nutrient solution for $30 \mathrm{~min}$, and drained off afterwards. The system had previously been employed for the treatment of methanol-containing air, reason why no start-up phase was observed with that pollutant. Still, as dimethylether had not previously been fed to this system, an initial two-week adaptation was performed, during which low dimethylether loads were fed. The study was divided in four stages, lasting two weeks long each, during which different stepwise increasing methanol loads (from 10 to $100 \mathrm{~g} \mathrm{~m}^{-3} \mathrm{~h}^{-1}$ ) and a constant dimethylether load (around $23 \mathrm{~g} \mathrm{~m}^{-3} \mathrm{~h}^{-1}$ ) were simultaneously fed. No other operation parameter was modified during the study. Table 1 shows the performance of the bioreactor during the study. 
Table 1.

Effect of the methanol load on the elimination capacities and removal efficiencies of methanol and dimethylether (start-up phase data not shown)

\begin{tabular}{|l|l||l|l|l|l|l||}
\hline Stage & $\begin{array}{l}\text { ML } \\
\left(\mathbf{g ~ m}^{-\mathbf{3}} \mathbf{h}^{-\mathbf{1}}\right)\end{array}$ & $\begin{array}{l}\text { MEC } \\
\left(\mathbf{g ~ m}^{-\mathbf{3}} \mathbf{h}^{\mathbf{- 1}} \mathbf{)}\right.\end{array}$ & $\begin{array}{l}\text { MRE } \\
\mathbf{( \% )}\end{array}$ & $\begin{array}{l}\text { DL } \\
\left(\mathbf{g ~ m}^{-\mathbf{3}} \mathbf{h}^{-\mathbf{1}} \mathbf{)}\right.\end{array}$ & $\begin{array}{l}\text { DEC } \\
\left(\mathbf{g ~ m}^{-\mathbf{3}} \mathbf{h}^{-\mathbf{1}} \mathbf{)}\right.\end{array}$ & $\begin{array}{l}\text { DRE } \\
\mathbf{( \% )}\end{array}$ \\
\hline 1 & $10 \pm 2$ & $10 \pm 2$ & $100 \pm 0$ & $24 \pm 2$ & $1.6 \pm 0.4$ & $6.9 \pm 1.7$ \\
\hline 2 & $26 \pm 4$ & $26 \pm 4$ & $100 \pm 1$ & $24 \pm 3$ & $1.3 \pm 1.0$ & $5.3 \pm 3.8$ \\
\hline 3 & $52 \pm 13$ & $51 \pm 12$ & $99 \pm 1$ & $23 \pm 4$ & $0.8 \pm 0.8$ & $3.2 \pm 3.0$ \\
\hline 4 & $100 \pm 22$ & $99 \pm 22$ & $99 \pm 1$ & $24 \pm 9$ & $0.6 \pm 0.3$ & $2.2 \pm 2.1$ \\
\hline
\end{tabular}

(Average value \pm standard deviation). ML: Methanol load. MEC: Methanol elimination capacity. MRE: Methanol removal efficiency. DL: Dimethylether load. DEC: Dimethylether elimination capacity. DRE: Dimethylether removal efficiency.

The results presented in Table 1 show that the elimination of methanol remained close to $100 \%$ even at the highest methanol load of $100 \mathrm{~g} \mathrm{~m}^{-3} \mathrm{~h}^{-1}$. This was already expected, as critical loads up to $280 \mathrm{~g} \mathrm{~m}^{-3} \mathrm{~h}^{-1}$ have been obtained in analogous experiments performed with methanol alone (Prado et al., 2005b). No significant differences were found between those studies and the present one, showing that the supply of low dimethylether loads does not affect the biodegradation of methanol under our operating conditions. This was also observed in batch studies carried out with mixtures of the two pollutants (results not shown). On the other hand, as Table 1 shows, the removal of dimethylether was very low during the study, reaching maximum elimination capacities around $2 \mathrm{~g} \mathrm{~m}^{-3} \mathrm{~h}^{-1}$ only, with removal efficiencies below $10 \%$. This is a consequence of its high Henry's constant and low solubility. A possible option to improve dimethylether treatment could be the supply of substances that improve its transfer to the liquid phase, as proposed by Hekmat and Vortmeyer (2000). Also, as observed in batch studies, dimethylether biodegradability is significantly lower than those of formaldehyde and methanol. A slight negative effect of the methanol load on the dimethylether removal efficiency is suggested by the data in Table 1.

Simultaneously to the previous experiment, another study was performed aimed at determining the influence of the formaldehyde load on the removal of mixtures of formaldehyde and dimethylether in a biotrickling filter. The system was packed with $2 \mathrm{l}$ lava rock and operated for two months at an EBRT of $72 \mathrm{~s}$. The biotrickling filter was continuously supplied a nutrient solution at a recirculation rate of $3 \mathrm{l} \mathrm{h}^{-1}$. The solution was renewed weekly, and its $\mathrm{pH}$ set at 7.5. The reactor had previously been employed for the treatment of gas-phase formaldehyde until the present experiment was started, reason why no adaptation phase was needed for this compound. However, with the purpose of adapting the microbes to the presence of dimethylether, low loads of this compound (between 0 and $6 \mathrm{~g} \mathrm{~m}^{-3} \mathrm{~h}^{-1}$ ) were initially fed to the reactor. The present study was started after approximately two weeks, once a stable dimethylether elimination had been reached. A constant dimethylether load (around $20 \mathrm{~g} \mathrm{~m}^{-3} \mathrm{~h}^{-1}$ ) and increasing formaldehyde loads (from 8 to $50 \mathrm{~g} \mathrm{~m}^{-3} \mathrm{~h}^{-1}$ ) were simultaneously supplied to the bioreactor. The results, presented in Table 2, show that an increase in the formaldehyde removal efficiency was observed when the formaldehyde load was increased. As exposed in Section 3.2, this unexpected effect can be attributed to a 
limitation in the pollutant mass transfer from the gas phase to the biofilm. Under our working conditions, the formaldehyde load had no effect on the removal of dimethylether. However, according to batch studies performed with mixtures of dimethylether and formaldehyde (not presented herein), it is expected that, at higher formaldehyde concentrations, the removal of dimethylether would be negatively affected.

Table 2.

Effect of the formaldehyde load on the elimination capacities and removal efficiencies of formaldehyde and dimethylether (start-up phase data not shown)

\begin{tabular}{|c|c|c|c|c|c|c|}
\hline Stage & $\begin{array}{l}\mathbf{F L} \\
\left(\mathrm{g} \mathrm{m}^{-3} h^{-1}\right)\end{array}$ & $\begin{array}{l}\text { FEC } \\
\left(\mathrm{g} \mathrm{m}^{-3} \mathrm{~h}^{-1}\right)\end{array}$ & $\begin{array}{l}\text { FRE } \\
(\%)\end{array}$ & $\begin{array}{l}\text { DL } \\
\left(\mathrm{g} \mathrm{m}^{-3} h^{-1}\right)\end{array}$ & \begin{tabular}{|l}
$\begin{array}{l}\text { DEC } \\
\left(\mathrm{g} \mathrm{m}^{-3} h^{-1}\right)\end{array}$ \\
\end{tabular} & \begin{tabular}{|l} 
DRE \\
$(\%)$
\end{tabular} \\
\hline 1 & $7.8 \pm 3.2$ & $2.4 \pm 2.2$ & $28 \pm 14$ & $22 \pm 7$ & $3.4 \pm 2.2$ & $15 \pm 8$ \\
\hline 2 & $20 \pm 3$ & $13 \pm 3$ & $66 \pm 8$ & $22 \pm 1$ & $5.5 \pm 1.7$ & $25 \pm 8$ \\
\hline 3 & $29 \pm 6$ & $19 \pm 4$ & $66 \pm 8$ & $21 \pm 5$ & $3.9 \pm 1.7$ & $19 \pm 8$ \\
\hline 4 & $48 \pm 4$ & $38 \pm 6$ & $79 \pm 8$ & $18 \pm 1$ & $3.6 \pm 0.7$ & $20 \pm 3$ \\
\hline
\end{tabular}

(Average value \pm standard deviation). FL: formaldehyde load, FEC: formaldehyde elimination capacity, FRE: formaldehyde removal efficiency, DL: dimethylether load, DEC: dimethylether elimination capacity, DRE: dimethylether removal efficiency.

Afterwards, the treatment of mixtures of formaldehyde, methanol and dimethylether was studied in a biotrickling filter packed with 21 lava rock. The system was operated for eight months under the same conditions as the biotrickling filter employed in the previous study, although an EBRT of $48 \mathrm{~s}$ was used during the first 10 days of operation. The system had previously been employed for the treatment of mixtures of formaldehyde and methanol. Hence, a fast start-up was expected for these compounds. However, in order to adapt the microbes to the presence of dimethylether, low dimethylether loads were fed to the reactor during two weeks before the experiment was started. In a first stage, very low methanol loads (always below $10 \mathrm{~g} \mathrm{~m}^{-3} \mathrm{~h}^{-1}$ ) were fed to the biotrickling filter, in order to minimize the inhibition caused by this compound on the biodegradation of dimethylether (Fig. 3). During the first 10 days of operation, formaldehyde and dimethylether loads were, respectively, near 42 and $0.6 \mathrm{~g} \mathrm{~m}^{-3} \mathrm{~h}^{-1}$. Average removal efficiencies around, respectively, $74 \%$ and $9.1 \%$ were obtained. In order to increase the removal efficiency of the system, on day 10 of operation the EBRT was increased up to a value of $72 \mathrm{~s}$, by means of a decrease of the gas flow rate from 150 to $100 \mathrm{l} \mathrm{h}^{-1}$. From that day on, and until day 37 of operation, the dimethylether load was gradually increased, with the purpose of inducing the production of specific enzymes for the elimination of this compound. Fig. 3 shows that, after a few days, a dimethylether-degrading microbial community developed inside the reactor. Still, the dimethylether removal efficiency remained low. Maximum dimethylether elimination capacities close to $10 \mathrm{~g} \mathrm{~m}^{-3} \mathrm{~h}^{-1}$ were attained and maintained during a few weeks with no significant variations. Between days 30 and 41 of operation, the formaldehyde load was gradually decreased, with no clear effect on the elimination of dimethylether. 

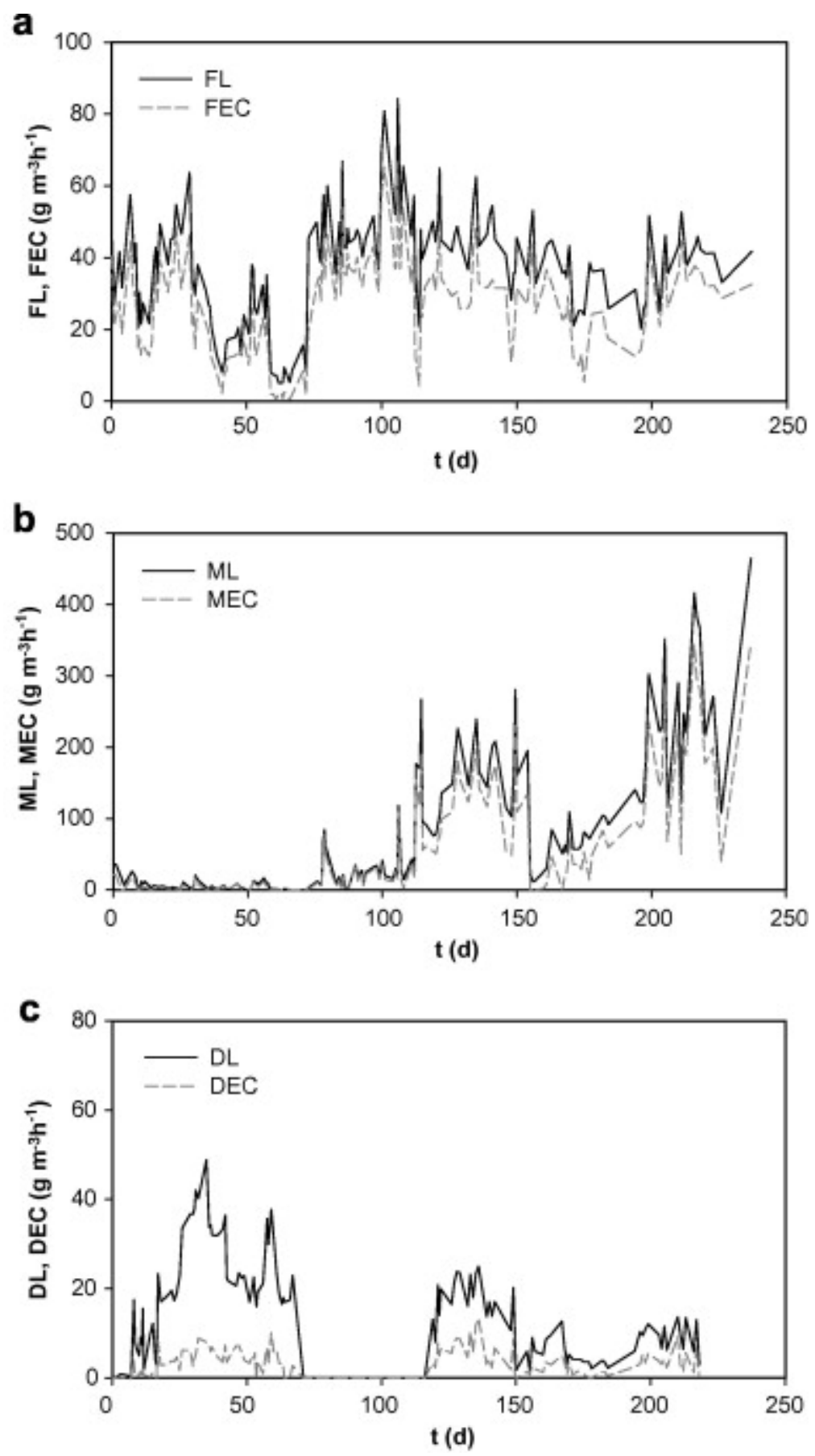

Fig. 3.

Long-term removal of mixtures of formaldehyde, methanol and dimethylether in a biotrickling filter. FL: formaldehyde load, FEC: formaldehyde elimination capacity, ML: methanol load, MEC: methanol elimination capacity, DL: dimethylether load, DEC: dimethylether elimination capacity.

In a second stage, which lasted between days 73 and 119, the dimethylether feed was stopped. The purpose of this was to check the survival of the dimethylether-degrading strains inside the bioreactor in the absence of that compound. Meanwhile, the formaldehyde and methanol loads were increased up to values close to 50 and $45 \mathrm{~g} \mathrm{~m}^{-3} \mathrm{~h}^{-1}$, respectively. Average elimination capacities of 37 and $33 \mathrm{~g} \mathrm{~m}^{-3} \mathrm{~h}^{-1}$ were obtained for formaldehyde and methanol, respectively, corresponding, in both cases, to removal efficiencies around $75 \%$. Once the dimethylether supply was restored, on day 
120, its biodegradation restarted immediately, proving the high stability of the dimethylether-degrading strains under unfavourable conditions. Afterwards, on day 157, the recirculation of the nutrient solution was stopped for three weeks. Hence, during this period the bioreactor was operated as a conventional biofilter. As shown in Fig. 3, no clear effect on its performance was observed. Although this proves that a reactor packed with an inert support can keep a constant performance for long periods of time with no liquid nor nutrient addition, long-term stability cannot be assured under such conditions (Prado et al., 2002). Finally, on day 183, the system was reinoculated with $2 \mathrm{l}$ fresh, non-adapted sludge. This resulted in an immediate decrease in the dimethylether elimination capacity, which remained low for the next 10 days. The removal of formaldehyde and methanol was not affected, as the sludge was already adapted to them.

\subsection{Treatment of mixtures of formaldehyde, methanol, dimethylether and carbon monoxide}

In a last study, the removal of mixtures of formaldehyde, methanol, dimethylether and carbon monoxide was studied in a conventional biofilter. Similar concentrations were fed to the reactor as those emitted from actual formaldehyde resin-producing industries, reaching up to $100 \mathrm{mg} \mathrm{m}^{-3}$ each for formaldehyde and methanol, and up to $50 \mathrm{mg} \mathrm{m}^{-3}$ each for dimethylether and carbon monoxide. The biofilter was packed with $1 \mathrm{l}$ lava rock and operated with a downward flow, at room temperature, for one month. As in the previous studies, it was weekly fed a nutrient solution. Three different EBRTs were assayed during this experiment, namely $58 \mathrm{~s}$ (between days 0 and 14), $41 \mathrm{~s}$ (days 1421), and 30 s (days 21-28). Fig. 4 shows the removal of all four compounds during the experimental run.
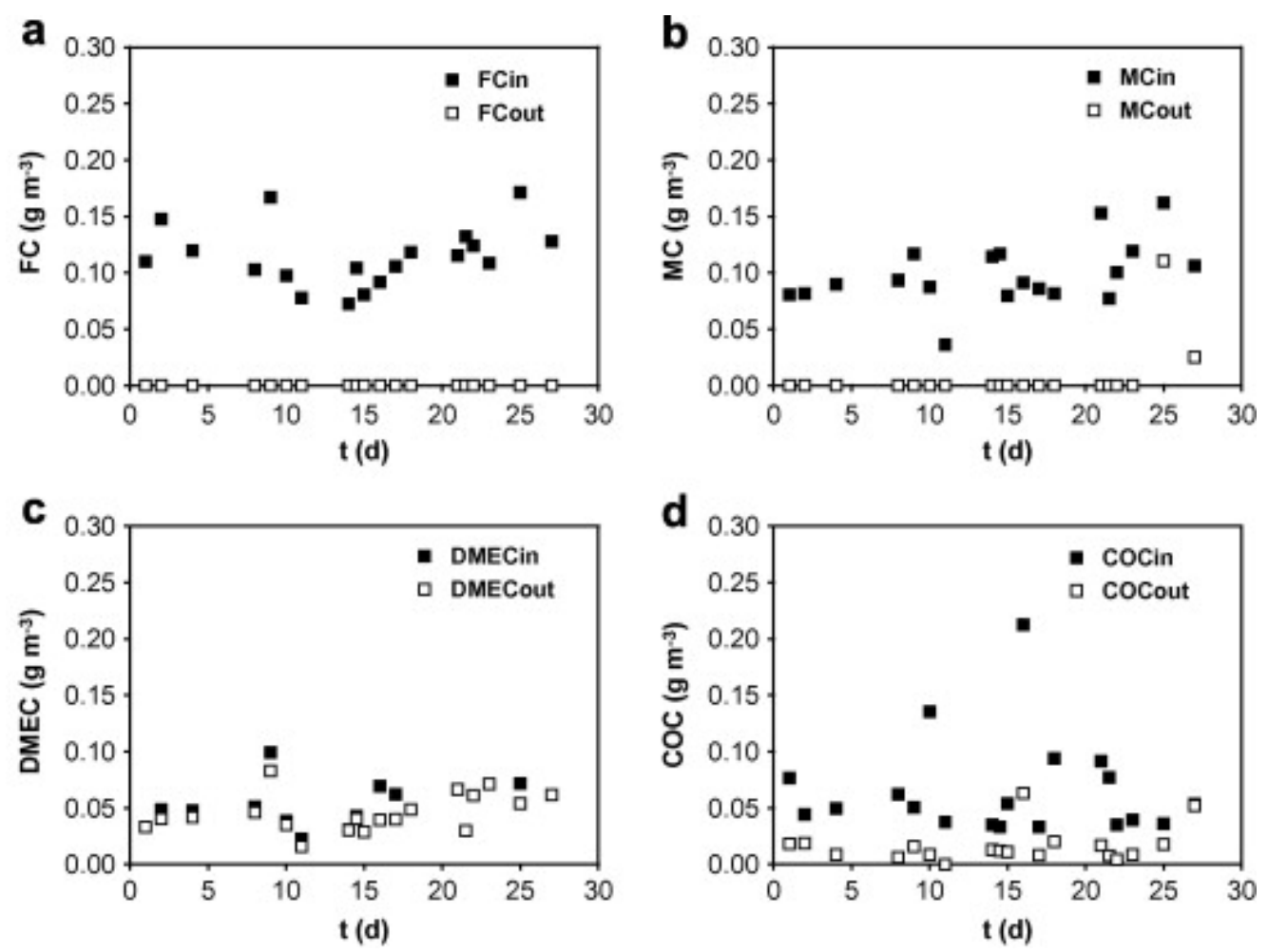

Fig. 4. Concentrations of each pollutant at the inlet and at the outlet of the bioreactor: (a) formaldehyde, (b) methanol, (c) dimethylether, (d) carbon monoxide. 
The results presented in Fig. 4 show that both formaldehyde and methanol were degraded with efficiencies close to $100 \%$ during most of the experiment. This is consistent with the results obtained in the previous studies. Also, the elimination of low concentrations of carbon monoxide was possible with removal efficiencies always above $60 \%$, proving that, at low inlet loads, its removal is feasible in biofilters, even when mixed with organic compounds. However, the performance of a series of similar bioreactors inoculated with pure cultures of $O$. carboxidovorans OM5 was not successful, as the strain was quickly overgrown by other invading organisms ( Prado et al., 2005a). On the other hand, the elimination of dimethylether was quite low during the study, as a consequence, mainly, of its poor biodegradability, and probably also due to its relatively low solubility in water. However, it is worth recalling that the toxicity and environmental impact of dimethylether is much weaker than that of the other compounds of the mixture. Fig. 5 shows how the decrease in the EBRT, from its original value of $58 \mathrm{~s}$ to $30 \mathrm{~s}$, led to a slight decay in the removal efficiencies of methanol, dimethylether and carbon monoxide. The removal of formaldehyde, however, was not clearly affected, which is consistent with results presented elsewhere ( Prado et al., 2004a).

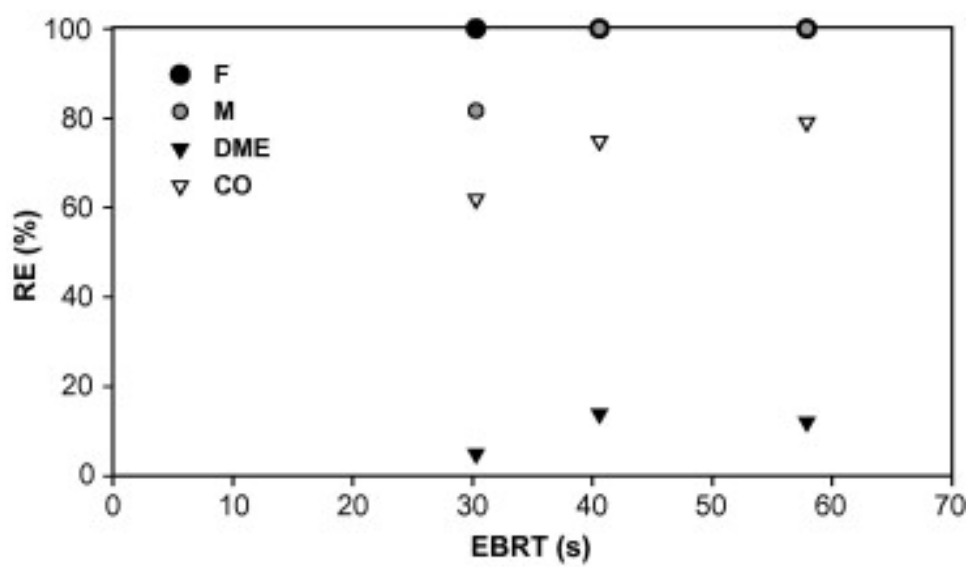

Fig. 5.

Effect of the EBRT on the removal efficiency of the four compounds. RE: removal efficiency.

\section{Conclusions}

The results presented herein prove that the biological treatment of waste gases containing mixtures of formaldehyde, methanol, dimethylether and carbon monoxide, the main pollutants present in gaseous emissions from formaldehyde resin-producing industries, can be carried out by means of biological technologies when the pollutants are present at concentrations similar to those observed in actual industrial emissions. Maximal average removal efficiencies of $100 \%, 100 \%, 12 \%$ and $80 \%$ were reached for formaldehyde, methanol, dimethylether and carbon monoxide, respectively, in a conventional biofilter packed with lava rock and operated at an EBRT of 1 min. Even though the global depuration of the mixture could probably be improved by means of the use of multistage systems or by adding substances that could improve the solubility of dimethylether and carbon monoxide, the high cost associated to these alternatives makes them inappropriate in industrial-scale reactors. Simpler and, hence, less expensive systems like a single-stage conventional biofilter would probably still be a better option for the removal of low concentrations of pollutants typically found in resin-producing industries. Additionally, a series of batch assays, in which aerobic 
sludge obtained from the wastewater treatment plant of one of these industries was employed as biocatalyst, demonstrated that the removal of formaldehyde and methanol is significantly faster than for dimethylether and carbon monoxide under similar conditions. An additional set of experiments, in which a pure culture of $O$. carboxidovorans OM5 was employed as biocatalyst for carbon monoxide removal, showed that the elimination of this compound was significantly enhanced with this specific microbial culture, even though its initial VSS concentration was around 10 times lower than that of the sludge used in the previous assays. However, the performance of conventional biofilters inoculated with a pure culture of this strain was worse than with sludge, due to the inability of this microorganism to effectively attach to the packing material and to compete with invading microorganisms.

It was proven that the use of hybrid two-stage bioreactors can overcome some of the problems commonly associated with the use of conventional biofilters (low or moderate maximum elimination capacities) and biotrickling filters (suboptimal removal efficiency) alone. When a mixture of formaldehyde and methanol, with average global loads around 20 and $270 \mathrm{~g} \mathrm{~m}^{-3} \mathrm{~h}^{-1}$, respectively, was fed to a hybrid biotrickling filterbiofilter system, average removal efficiencies above 99\% were obtained for both pollutants in the two-stage bioreactor. As expected, even though both reactors had the same volume, more than $70 \%$ of the degradation took place in the first stage, the biotrickling filter, while the remainder off-gas was fully depurated in the second stage, the conventional biofilter.

The results obtained with a series of bioreactors fed gaseous mixtures of formaldehyde, methanol and dimethylether under different conditions allow to conclude that the elimination capacity of the latter is significantly lower than those of formaldehyde and methanol, as a consequence of its lower solubility in water and slow biodegradation. Maximum dimethylether elimination capacities around $10 \mathrm{~g} \mathrm{~m}^{-3} \mathrm{~h}^{-1}$ were obtained and maintained during a few weeks, although during most of the study, the average

dimethylether elimination capacity was usually below $5 \mathrm{~g} \mathrm{~m}^{-3} \mathrm{~h}^{-1}$. However, considering the relatively low toxicity and environmental impact of the compound, these results can be considered satisfactory.

\section{Acknowledgements}

The present research was funded by project PPQ 2001-0557 of the Spanish Ministry of Education and Culture. The authors are also indebted to Dr. O. Meyer of the University of Bayreuth, Germany, for supplying the original Oligotropha carboxidovorans OM5 culture.

\section{References}

J.M. Chen, J. Wang, J.F. Ma

Effects of gas flow-rate and inlet concentration on nitric oxide removal in a autotrophic biofilter

J. Chem. Technol. Biotechnol., 81 (2006), pp. 812-816 
D.E. Chitwood, J.S. Devinny, F.E. Reynolds

Evaluation of a two-stage biofilter for treatment of POTW waste air

Environ. Prog., 18 (1999), pp. 212-221

D.S. Choi, J.S. Devinny, M.A. Deshusses

Behavior of field-scale biotrickling filter under nonsteady state conditions

J. Environ. Eng. - ASCE, 130 (2004), pp. 322-328

M. Eiroa, A. Vilar, C. Kennes, M.C. Veiga

Formaldehyde biodegradation in the presence of methanol under denitrifying conditions

J. Chem. Technol. Biotechnol., 81 (2006), pp. 312-317

E. Estévez, M.C. Veiga, C. Kennes

Biodegradation of toluene by the new fungal isolates Paecilomyces variotii and Exophiala oligosperma

J. Ind. Microbiol. Biotechnol., 32 (2005), pp. 33-37

D. Gabriel, M.A. Deshusses

Retrofitting existing chemical scrubbers to biotrickling filters for $\mathrm{H}_{2} \mathrm{~S}$ emission control

Proc. Natl. Acad. Sci., 100 (2003), pp. 6308-6312

D. Hekmat, D. Vortmeyer

Biodegradation of poorly water-soluble volatile aromatic compounds from waste air

Chem. Eng. Technol., 23 (2000), pp. 315-318

Hsu, S.K., Lai, T.J., Hsu, T.H., 2004. Performance study of a two-stage biofilter on volatile organic compounds from a polyurethane resin manufacturing factory. In: Devinny, J.S. (Ed.), Proceedings of the 2004 Conference on Biofiltration for Air Pollution Control, Redondo Beach, CA, USA, pp. 67-72.

Y. Jin, M.C. Veiga, C. Kennes

Bioprocesses for the removal of nitrogen oxides from polluted air

J. Chem. Technol. Biotechnol., 80 (2005), pp. 483-494

C. Kennes, F. Thalasso

Waste gas biotreatment technology

J. Chem. Technol. Biotechnol., 72 (1998), pp. 303-319

C. Kennes, M.C. Veiga

Bioreactors for Waste Gas Treatment

Kluwer Academic Publisher, Dordrecht, The Netherlands (2001) p. 312

C. Kennes, M.C. Veiga

Inert filter media for the biofiltration of waste gases - characteristics and biomass control

Rev. Environ. Sci. Biotechnol., 1 (2002), pp. 201-214

C. Kennes, M.C. Veiga

Fungal biocatalysts in the biofiltration of VOC-polluted air

J. Biotechnol., 113 (2004), pp. 305-319 
S. Krailas, Q. Tuan Pham, R. Amal, J.K. Jiang, M. Heitz

Effect of inlet mass loading, water and total bacteria count on methanol elimination using upward flow and downward flow biofilters

J. Chem. Technol. Biotechnol., 75 (2000), pp. 299-305

E.Y. Lee

Continuous treatment of gas-phase trichloroethylene by Burkholderia cepacia G4 in a two-stage continuous stirred tank reactor/trickling biofilter system

J. Biosci. Bioeng., 96 (2003), pp. 572-574

H. Li, J.R. Mihelcic, J.C. Crittenden, K.A. Anderson

Field measurements and modeling of two-stage biofilter that treats odorous sulfur air emissions

J. Environ. Eng. - ASCE, 129 (2003), pp. 684-692

J. Máckowiak

Abschiedung von formadehyd aus der abluft im biofilter

A.J. Dragt, J. van Ham (Eds.), Biotechniques for Air Pollution Abatement and Odour Control Policies, Elsevier, Amsterdam, The Netherlands (1992), pp. 273-278

O. Meyer, H.G. Schlegel

Oxidation of carbon monoxide in cell extracts of Pseudomonas carboxydovorans

J. Bacteriol., 137 (1979), pp. 811-817

M. Mohseni, D.G. Allen

Biofiltration of mixtures of hydrophilic and hydrophobic volatile organic compounds

Chem. Eng. Sci., 55 (2000), pp. 1545-1558

T. Nash

The colorimetric estimation of formaldehyde by means of the Hantzch reaction

Biochem. J., 55 (1953), pp. 416-421

W.J.H. Okkerse, S.P.P. Ottengraf, R.M.M. Diks, B. Osinga-Kuipers, P. Jacobs

Long term performance of biotrickling filters removing a mixture of volatile organic compounds from an artificial waste gas: dichloromethane and methylmethacrylate

Bioprocess Eng., 20 (1999), pp. 49-57

A.R. Pedersen, S. Møller, S. Molin, E. Arvin

Activity of toluene-degrading Pseudomonas putida in the early growth phase of a biofilm for waste gas treatment

Biotechnol. Bioeng., 54 (1997), pp. 131-141

Philip, L., Deshusses, M.A., 2002. Biological treatment of $\mathrm{NO}_{x}$ and $\mathrm{SO}_{2}$. In: Proceedings of the 95th Air and Waste Management Association's Annual Conference and Exhibition. Baltimore, MD, USA.

Ó.J. Prado, J.A. Mendoza, M.C. Veiga, C. Kennes

Optimization of nutrient supply in a downflow gas-phase biofilter packed with an inert carrier

Appl. Microbiol. Biotechnol., 59 (2002), pp. 567-573 
Ó.J. Prado, M. Eiroa, M.C. Veiga, C. Kennes

Bioreactors for the treatment of industrial waste gases containing formaldehyde and other aliphatic compounds in: S.N. Agathos, W. Reineke (Eds.), Focus on Biotechnology, Biotechnology for the Environment: Wastewater Treatment and Modeling, Waste Gas Handling, vol. 3C, Kluwer Academic Publishers, Dordrecht, The Netherlands (2003), pp. 259-273

Ó.J. Prado, M.C. Veiga, C. Kennes

Biofiltration of waste gases containing a mixture of formaldehyde and methanol Appl. Microbiol. Biotechnol., 65 (2004), pp. 235-242

Prado, Ó.J., Veiga, M.C., Kennes, C., 2004b. Biofiltration of waste gases from a synthetic resin-producing industry. In: 2004 USC-CSC-TRG Conference on Biofiltration. Redondo Beach, CA, USA.

Prado, Ó.J., Veiga, M.C., Kennes, C., 2005a. Biological treatment of mixtures of toxic compounds emitted from formaldehyde resin-producing industries. In: Kennes, C., Veiga, M.C. (Eds.), Proceedings of the International Congress on Biotechniques for Air Pollution Control. Servizo de Publicacións da Universidade da Coruña. A Coruña, Spain, pp. 391-396.

Ó.J. Prado, M.C. Veiga, C. Kennes

Treatment of gas-phase methanol in conventional biofilters packed with lava rock

Water Res., 39 (2005), pp. 2385-2393

Ó.J. Prado, M.C. Veiga, C. Kennes

Effect of key parameters on the removal of formaldehyde and methanol in gas-phase biotrickling filters

J. Hazard. Mater., 138 (2006), pp. 543-548

A. Ruokojarvi, J. Ruuskanen, P.J. Martikainen, M. Olkkonen

Oxidation of gas mixtures containing dimethyl sulfide, hydrogen sulfide, and methanethiol using a two-stage biotrickling filter

J. Air Waste Manage., 51 (2001), pp. 11-16

Z. Shareefdeen, B.C. Baltzis, Y.S. Oh, R. Bartha

Biofiltration of methanol vapor

Biotechnol. Bioeng., 41 (1993), pp. 512-524

G. Spigno, C. Pagella, D. Fumi, R. Molteni, D.M. de Faveri

VOCs removal from waste gases: gas-phase bioreactor for the abatement of hexane by Aspergillus niger

Chem. Eng. Sci., 58 (2003), pp. 739-746

Van Groenestijn, J.W., 2005. Biotechniques for air pollution control: past, present and future trends. In: Kennes, C., Veiga, M.C. (Eds.), Proceedings of the International Congress on Biotechniques for Air Pollution Control. Servizo de Publicacións da Universidade da Coruña. La Coruña, Spain, pp. 3-12. 
E.J. Wolfrum, A.S. Watt

Bioreactor design studies for a hydrogen-producing bacterium

Appl. Biochem. Biotechnol., 98 (2002), pp. 611-625

Wolfrum, E.J., Watt, A.S., Huang, J., 2002. Bioreactor development for biological hydrogen production. In: Proceedings of the 2002 US DOE Hydrogen Program Review. Golden, CO, USA. 